\title{
Broad spectrum pesticide application alters natural enemy communities and may facilitate secondary pest outbreaks
}

\author{
Matthew P Hill ${ }^{\text {Corresp.. }}{ }^{1}$, Sarina Macfadyen ${ }^{1}$, Michael A Nash ${ }^{2}$ \\ ${ }^{1}$ Agriculture \& Food, CSIRO, Canberra, Australian Capital Territory, Australia \\ ${ }^{2}$ School of Agriculture, Food and Wine, University of Adelaide, Waite Campus, South Australia, Australia \\ Corresponding Author: Matthew P Hill \\ Email address: matthill@protonmail.com
}

Background. Pesticide application is the dominant control method for arthropod pests in broad-acre arable systems. In Australia, organophosphate pesticides are often applied either prophylactically, or reactively, including at higher concentrations, to control crop establishment pests such as false wireworms and earth mite species. Organophosphates are reported to be disruptive to beneficial species, such as natural enemies, but this has not been widely assessed in Australian systems. Neither has the risk that secondary outbreaks may occur if the natural enemy community composition or function is altered.

Methods. We examine the abundance of ground-dwelling invertebrate communities in an arable field over successive seasons under rotation; barley, two years of wheat, then canola. Two organophosphates (chlorpyrifos and methidathion) were initially applied at recommended rates. After no discernible impact on target pest species, the rate for chlorpyrifos was doubled to elicit a definitive response to a level used at establishment when seedling damage is observed. Invertebrates were sampled using pitfalls and refuge traps throughout the experiments. We applied measures of community diversity, principal response curves and multiple generalised linear modelling techniques to understand the changes in pest and natural enemy communities.

Results. There was large variability due to seasonality and crop type. Nevertheless, both pest (e.g. mites and aphids) and natural enemy (e.g. predatory beetles) invertebrate communities were significantly affected by application of organophosphates. When the rate of chlorpyrifos was increased there was a reduction in the number of beetles that predate on slug populations. Slugs displayed opposite trends to many of the other target pests, and actually increased in numbers under the higher rates of chlorpyrifos in comparison to the other treatments. Slug numbers in the final rotation of canola resulted in significant yield loss regardless of pesticide application.

Discussion. Organophosphates are a cost-effective tool to control emergent pests in broad-acre arable systems in Australia. We found risks associated with prophylactic application in fields under rotation between different crop types and significant changes to the community of pests and natural enemy. Disrupting key predators reduced effective suppression of other pests, such as slugs, and may lead to secondary outbreaks when rotating with susceptible crops such as canola. Such non-target impacts are rarely documented when studies focus on single-species, rather than community assessments. This study represents a single demonstration of how pesticide application can lead to secondary outbreaks and reinforces the need for studies that include a longer temporal component to understand this process further. 
1 Broad spectrum pesticide application alters natural enemy communities and may facilitate 2 secondary pest outbreaks

3 Organophosphates and invertebrates

4

5 Matthew P. Hill ${ }^{*}$, Sarina Macfadyen ${ }^{1}$, Michael A. Nash ${ }^{2}$

6

$7 \quad{ }^{1}$ CSIRO Agriculture \& Food, Canberra, Australian Capital Territory, Australia

$8{ }^{2}$ School of Agriculture, Food and Wine, University of Adelaide, Waite Campus, South Australia,

9 Australia

10

11

$12 *$ matthill@protonmail.com

13

14 


\section{Abstract}

Background.

17 Pesticide application is the dominant control method for arthropod pests in broad-acre arable systems. In Australia, organophosphate pesticides are often applied either prophylactically, or reactively, including at higher concentrations, to control crop establishment pests such as false wireworms and earth mite species. Organophosphates are reported to be disruptive to beneficial species, such as natural enemies, but this has not been widely assessed in Australian systems.

22 Neither has the risk that secondary outbreaks may occur if the natural enemy community 23 composition or function is altered.

\section{Methods.}

25 We examine the abundance of ground-dwelling invertebrate communities in an arable field over successive seasons under rotation; barley, two years of wheat, then canola. Two organophosphates (chlorpyrifos and methidathion) were initially applied at recommended rates. After no discernible impact on target pest species, the rate for chlorpyrifos was doubled to elicit a definitive response to a level used at establishment when seedling damage is observed. Invertebrates were sampled using pitfalls and refuge traps throughout the experiments. We applied measures of community diversity, principal response curves and multiple generalised linear modelling techniques to understand the changes in pest and natural enemy communities.

\section{Results.}

34 There was large variability due to seasonality and crop type. Nevertheless, both pest (e.g. mites and aphids) and natural enemy (e.g. predatory beetles) invertebrate communities were significantly affected by application of organophosphates. When the rate of chlorpyrifos was increased there was a reduction in the number of beetles that predate on slug populations. Slugs displayed opposite trends to many of the other target pests, and actually increased in numbers under the higher rates of chlorpyrifos in comparison to the other treatments. Slug numbers in the final rotation of canola resulted in significant yield loss regardless of pesticide application.

\section{Discussion.}


42 Organophosphates are a cost-effective tool to control emergent pests in broad-acre arable 43 systems in Australia. We found risks associated with prophylactic application in fields under 44 rotation between different crop types and significant changes to the community of pests and 45 natural enemy. Disrupting key predators reduced effective suppression of other pests, such as 46 slugs, and may lead to secondary outbreaks when rotating with susceptible crops such as canola.

47 Such non-target impacts are rarely documented when studies focus on single-species, rather than 48 community assessments. This study represents a single demonstration of how pesticide 49 application can lead to secondary outbreaks and reinforces the need for studies that include a 50 longer temporal component to understand this process further. 
52

53

54

55

56

57

\section{Introduction}

Pesticides predominate management options for control of invertebrate pests in many parts of the world (Thomson \& Hoffmann, 2006; Guedes et al., 2016). The most widely used pesticide class in Australia is organophosphates, with $\sim 5,000$ tonnes applied annually across agricultural systems in 2002 (Radcliffe, 2002). Despite an increase in use of pesticides, crop losses due to pests have remained largely unchanged for 30-40 years (Altieri \& Nicholls, 2004). Beyond the target pests, broad-spectrum pesticides (that kill insects and mites indiscriminately) may affect non-target invertebrate species (Readshaw, 1975), including causing reductions in natural enemy population abundance and activity (e.g. Wilson et al., 1998; 1999), and competition between pest species (known as competitive release, Zeilinger et al., 2016). Assays of invertebrates against weathered residues have shown the persistence of pesticides might play an important part in their negative impacts on natural enemies in the field (Grundy et al., 2000).

A potential outcome of frequent broad-spectrum pesticide use is the emergence of pests not controlled by the pesticides but benefiting from reduced mortality from natural enemies and/or competitive release, commonly known as secondary pests (Dutcher, 2007; Gross \& Rosenheim 2011; Steinmann et al, 2011). Reporting secondary pest outbreaks is challenging as they may also be caused by other mechanisms, which inherently makes it difficult to determine how frequently pesticide-use results in this outcome (Gross \& Rosenheim 2011). In cotton fields, it was estimated that $20 \%$ of late-season pesticide costs were attributable to secondary pest outbreaks caused by early-season pesticide applications for Lygus pests (Gross \& Rosenheim 2011). Higher numbers of cotton aphids, Aphis gossypii Glover and spider mites, Tetranychus urticae Koch were found in cotton fields that received early-season applications of insecticides against Helicoverpa spp. (Wilson et al., 1998, 1999). Understanding interactions between resident invertebrate communities and pesticides will help us predict when secondary pest outbreaks are likely to occur, and lead to more informed pest control decision-making.

One standardised approach for assessing non-target impacts of pesticides is the International Organization for Biological and Integrated Control - Pesticides and Beneficial Organisms (IOBC) ratings system (Hassan, 1985). This approach has identified a range of toxic and harmful effects of broad-spectrum pesticides on a number of non-target invertebrate species, particularly 
83 natural enemies. As this ratings system focuses on standardised sets of "representative"

84 organisms, it does not consider the specific context in which pesticides are being applied, the rate

85 at which they are applied nor the cumulative effects of multiple chemical applications across a

86 season (Nash et al., 2008a). This means that the diverse range of sub-lethal effects are not

87 assessed (Stark et al., 2004). Subsequently, more bioassays under field conditions are needed to 88 incorporate the dynamic interaction between pest populations and their natural enemy communities (Thomson \& Hoffmann, 2007) and the environmental context at the time of application. While such studies are rare for examining repeated pesticide applications in arable systems, community-level analyses to examine the effects of genetically modified crops (e.g. Bt cotton) on non-target species are more commonplace (Naranjo 2005; Whitehouse et al., 2007; Rose \& Dively, 2007). This suggests that such methods should be transferable to examine repeated pesticide applications on communities of pests and natural enemies within Australian arable systems.

In Australian broad-acre grains the pest management practitioners are primarily concerned with pesticide efficacy, crop phytotoxicity and cost; seldom are broader impacts of pesticides included in decision-making (van der Werf, 1996; Umina et al., 2015). As such, more expensive selective pesticides are not favoured. Two broad-spectrum organophosphate pesticides, methidathion and chlorpyrifos, are commonly used to control invertebrate pests. Methidathion is typically used to control earth mites and lucerne flea in emerging canola crops, and chlorpyrifos is used to control mite and wireworm larvae around sowing (Gu et al. 2007). Chlorpyrifos is applied for the control of pests such as earwigs, isopods (Armadillidiidae) and millipedes (Portuguese millipede, Ommatoiulus moreleti Lucas, 1860) (MA Nash personal observations), despite not being registered specifically to control those pests. A reduced application rate of broad-spectrum pesticides may lessen the impact on natural enemies, but still remain efficacious against pests

108 (e.g. Wiles \& Jepson 1995; Wilson et al., 1998). However, when growers fail to achieve what they consider to be adequate pest control they often respond by applying higher rates of pesticides, especially for high yielding crops that are likely to still generate a significant profit

111 despite the added input costs (Edwards et al., 2008). Repeated applications of broad-spectrum

112 pesticides to control typical pest species is common in broad-acre crops, in particular canola $(\mathrm{Gu}$ 113 et al., 2007) and pulses (Murray et al., 2013). There are few economic thresholds for many pest 
114 species common in Australian grain crops (but see Arthur et al., 2015), therefore growers cannot

115 often relate the pest numbers observed in a field to likely yield losses and adjust pesticide

116 application accordingly (e.g. aphids; Valenzuela \& Hoffmann 2015). The outcome is that

117 pesticides are often applied prophylactically or in response to some observed crop damage that

118 may or may not result in yield loss.

119

120 Since the late 1990s, a number of exotic slug species have also emerged as pests of canola at the 121 crop establishment stage across the high rainfall ( $>500 \mathrm{~mm}$ growing season rainfall) zones of 122 southern Australia (Nash et al., 2007). Two common species, Deroceras reticulatum Müller,

1231774 and Milax gagates Draparnaud, 1801, can inflict significant damage to canola crops before 124 the four-leaf stage leading to plant death (Nash et al., 2007). The increased pest status of slugs is 125 often attributed to the retention of crop residues which serve as habitat and food (Glen, 1989). It

126 may also be due to a reduction in key predator numbers (e.g. predatory beetles Carabidae and

127 Staphylinidae) or a change in broader predator communities (including spiders, ladybeetles,

128 lacewings, predatory mites) as a result of widespread pesticide use (Nash et al., 2008a), including

129 insecticidal seed treatments (Douglas et al., 2015)

131 To predict the impact of pesticides on the interaction between pest species abundance, natural

132 enemy abundance, and crop yield we analyse the change in ground-dwelling invertebrate

133 community composition under application of organophosphates and across a rotation sequence in 134 a commercial grain field. We first investigate how the prophylactic use of pesticides to control 135 earth mites at the establishment stage of crops impacts both pest and natural enemy invertebrate 136 communities. Secondly, we investigate whether structural change to the natural enemy

137 invertebrate community over a period of three seasons led to the outbreak of secondary pest 138 species, in this case slugs. We make an assessment of the yield effects that may be attributed to 139 the trade-offs involved in pesticide applications and discuss both how our data support IOBC 140 ratings, and how growers could use this information in decision-making. 


\section{Materials \& Methods}

\section{Study site and experimental design}

144 The study site was situated near Mortlake, Victoria, Australia $\left(38^{\circ} 00.5^{\prime} \mathrm{S}, 142^{\circ} 45.3^{\prime} \mathrm{E}\right)$, which

145 has a temperate climate with mean maximum annual temperature of $18-21^{\circ} \mathrm{C}$ and mean annual

146 precipitation is $625 \mathrm{~mm}$. The soils are predominantly of grey sodosols (Isbell, 1996) based on

147 quaternary basalt. The experimental area was located in a 36 ha field managed according to

148 standard district agricultural practices using $2 \mathrm{~m}$ wide raised $(20 \mathrm{~cm})$ beds, constructed to alleviate

149 water logging. To limit confounding non-target impacts from other chemicals, no seed treatments

150 or fungicides were used during this trial, however herbicides were applied. The field was divided

151 into $72 \mathrm{~m}$ wide strips and each was allocated to one of three treatments; methidathion (Supracide

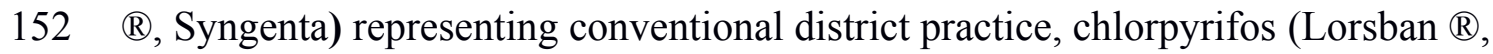

153 DowAgroScience) representing a supposedly more disruptive treatment, and $801 /$ ha of water as

154 a control (Fig. 1). The dates of sowing and treatment applications, and the seasonal weather

155 conditions for each year are shown in Table 1. In 2004 and 2005 the pesticides were applied at

156 recommended field rates of $40 \mathrm{~g}$ active ingredient (a.i.) /ha for methidathion and $250 \mathrm{~g}$ a.i./ha for

157 chlorpyrifos. Field observations indicated that treatments did not control pests in 2005-2006, so

158 the rate of chlorpyrifos was increased to $500 \mathrm{~g}$ a.i. / ha for 2006 and 2007. This double rate was

159 selected as it i) reflected grower practice when responding to a multitude of establishment pests,

160 and ii) may increase disruption to natural enemy communities through an increase in the

161 magnitude of exposure to a known toxicant (Table 2). This provided an assessment of the effect

162 of increased application rates on the pest and natural enemy community and is similar to real-

163 world practices where pesticide spray rates are increased in response to visible signs of high pest

164 abundance, and/or damage.

165

166 Invertebrate sampling

167 Since 2005, three transects (henceforth referred to as blocks) were laid out perpendicular to the 168 treatment strips, so that each bisected the three treatments, achieved maximum interspersion of 169 treatments and achieved spatial independence (Fig. 1). The edges of the strips were avoided by 170 sampling towards the middle of the $72 \mathrm{~m}$ wide strip. In each block, five census points (12m apart) 
171 were selected per replicate (total of $5 \times 3 \times 3$ census points). Each census point consisted of four

172 pitfall traps (7 cm deep by $11 \mathrm{~cm}$ in diameter filled $190 \mathrm{ml}$ ethylene glycol) to capture macro-

173 invertebrates $(>2 \mathrm{~mm})$, and four surface refuge traps to capture slugs $(300 \mathrm{~mm}$ by $300 \mathrm{~mm}$

174 terracotta paving tile placed on the soil surface as per Nash et al., 2007). While these sampling

175 methods are not optimal for all macro-invertebrates in the field, it does allow for an assessment

176 of the ground-active communities.

177 Sampling was conducted three times a year to coincide with crop establishment (Zadok's Growth

178 Stage 1) (herein referred to as winter), stem elongation (Zadok's Growth Stage 3) herein referred

179 to as spring) and post-harvest (herein referred to as summer) (Table 1). Traps at each census

180 point were established after sowing and opened for one week, before being closed until later

181 sampling when reopened for one week. The pitfall trap catch was returned to the laboratory and

182 sieved (200 $\mu \mathrm{m}$ mesh) prior to sorting under a dissection microscope. The refuge traps were

183 turned over in the field and the number and identity of the slugs on the underside recorded in the

184 field, then all individuals were removed with a subset retained in $70 \%$ ethanol as vouchers.

185 From the invertebrate data collected in the pitfall traps we defined two functional communities,

186 pests and natural enemies, and examined changes within these two broad groups as well as

187 targeted analysis on individual species or taxa (Table 2). As some taxa such as millipedes and

188 earwigs may sometimes act as either pest or natural enemy it can be difficult to broadly classify

189 them at this level. Here we assigned them as pests as they may inflict damage, but may also act

190 as natural enemies at certain times. Taxa such as ants (Formicidae) are also hard to assign to one

191 of these two groups in this system, as they perform roles outside of pests and natural enemies,

192 and so were omitted from subsequent analysis. For some common pest and natural enemy

193 species, their identification is straightforward. However, for many taxa we lack species

194 descriptions (especially for immature stages) and in these cases family-level identification was

195 conducted.

196 Yield

197 Yield of the crops grown during this study were recorded using Advanced Farming Systems

198 (AFS) features available for Case IH combine harvester, with different machines being used over

199 the course of the study. The software recorded clean grain flow and moisture whilst harvesting,

200 along with geographic co-ordinates (WGS 84). The data was calibrated in accordance with 
201 individual user manuals, but to ensure accuracy actual weights obtained from point of sale were 202 used to correct data to tonnes/ha for each season. Initial data handling and maps were developed 203 using the SMS ${ }^{\mathrm{TM}}$ Advanced Software Ver. 8.0 (Ag Leader Technology ${ }^{\circledR}$, Ames, Iowa). Spatial

204 yield data was gridded using kriging with the default settings (linear variogram) in SurferC Ver. 2058.05 (Golden Software, Inc. Colorado), to create contour maps to compare with the invertebrate 206 samples collected in the transects. Because of differences in collection of spatial data, tolerances 207 were set at $10 \mathrm{~m}^{2}$ for yield data, and $6 \mathrm{~m}^{2}$ for invertebrate census points, not all points overlayed 208 exactly so corresponding data was matched and extracted manually. Geographic referenced 209 information was converted to Cartesian coordinates using the software GEOD Ver. 3.42

210 (Graham Samuel \& Associates Pty Ltd, Charlestown, NSW).

\section{Statistical Analyses}

212 Due to the strip treatments being inherently wide (resulting from the equipment used), it was not 213 possible to randomise the treatments within a block, making spatial non-independance a potential 214 issue. Prior to the final choice of methods, we conducted some preliminary analysis of our data 215 using a very conservative approach (generalised estimating equations (GEE); Dormann et al. 216 2007). In this approach, edge groups of 4 traps were included and, or, excluded to check for 217 migration and compensate for spatial non-independence. We found that data did not violate 218 assumptions (GEE run with and without an autoregressive function for position within treatment 219 strip gave the same conclusion) and migration between treatment strips was not detected. These 220 preliminary analyses supported that populations here had a random distribution, and

221 independence, and that there was not a requirement to randomise the treatments.

222 We calculated species richness as total number of taxa present (prior to defining pests and 223 natural enemy communities), for each sample across treatments and sampling times to examine 224 overall effects of pesticide application across the study period. We assumed that each taxa 225 represented one species (even if sorted to family-level), although this is likely to underestimate 226 species diversity. We calculated species turnover within each treatment through time, using the 227 "codyn" package in R (Hallett et al., 2016). This analysis allows for the total turnover to be 228 calculated per time point (i.e. the proportion of species that differ between time points either by 229 appearing or disappearing), but also the proportion of species that appear and disappear at each 230 time point. We then examined the mean rank shifts for each treatment, which give an indication 
231 of the degree of species reordering between two time points, again using the codyn package

232 (Hallett et al., 2016).

233 To examine the effects of pesticide on both pest and natural enemy communities, we employed

234 two different methods that have recently been evaluated for use in ecotoxicology (Szöcs et al.,

235 2015). The first of these are principle response curves (PRC; Van den Brink \& Ter Braak, 1999),

236 which are widely used in freshwater mesocosm studies and pest-resistant crops such as $B t$ cotton,

237 to examine community level response to pesticides (or control strategies) over time (e.g. Naranjo

238 2005; Whitehouse et al., 2007; Rose \& Dively, 2007. A PRC is a time-dependent multivariate

239 technique based on RDA (redundancy analysis). By incorporating treatment, time and the

240 interaction thereof, a PRC allows for visualizations of a treatment effect through time on

241 community structure, by highlighting variance in overall response. We used the function "prc" in

242 the R package "vegan" to conduct these analyses. To evaluate the significance of treatment at

243 each sampling point, we conducted single RDAs and used a permutation structure to account for

244 the blocked design of the study.

245 The second method fits separate generalised linear models (GLMs) to each species, to give an

246 overall community analysis (Wang et al., 2012) and has recently been applied to investigate

247 pesticide effects on communities (Szöcs et al., 2015). By using poisson or negative binomial

248 distributions, GLMs are able to handle to count data without the need for data transformation.

249 Methods that incorporate GLMs appear to be particularly suited for identifying responding taxa

250 that would be missing on the first axis in the PRC (Szöcs et al., 2015). Principal response curves

251 appear to describe the direction of the effect on the community more clearly, thus using PRC and

252 GLMs together allows for complimentary analysis on community and treatment data through

253 time. Using the R package "mvabund" and function "manyglm" we ran separate GLM per

254 species, using negative binomial distributions, for the two communities (pests and natural

255 enemies), with the three treatments and time points, and the interaction thereof, as the dependent

256 variables. We compared models incorporating treatment and time to models without to

257 investigate the overall effect of treatment, and to investigate the interaction of treatment and

258 time. Finally, we performed separate analyses at each sampling time point to examine

259 differences between communities for each treatment, using Likelihood Ratio tests on the

260 univariate responses (species) and 2000 bootstrap repeats. To visualise changes in the pest and 
261 natural enemy communities in response to the treatments, described through the GLM analyses,

262 we plotted the combined deviance (effect size) for the members of each community across each

263 of the sampling points.

264 Assessing the ultimate impact of the pesticide treatments on crop yield was challenging due to 265 the large seasonal fluctuations in conditions for crop growth and underlying spatial patterns in

266 crop productivity across large fields. However, ideally every pesticide input should provide some

267 yield benefit for the grower each year, regardless of seasonal conditions, usually through

268 protecting the crop from damage due to pests. In our study this should manifest as a significant

269 increase in crop yield in the treated parts of the field in comparison to the control area. Prior to

270 analysis of yield we removed outliers (high values for yield) that corresponded to instances

271 where the header stops during harvest and extra ingrain is collected. These outliers were

272 identified as being further than two standard deviations from the mean, per block, per year. We

273 then performed separate season GLMs with the yield as response, and treatment and block as

274 fixed effects, including the interaction between treatment and block. As there was almost always

275 a significant interaction, pairwise contrasts using the "lsmeans" package in R, were used to

276 determine where treatments differed within blocks.

277

278 Results

279 In total 115 different species or taxa were identified from our samples: This included 10 species 280 of carabid mostly belonging to the subfamilies Broscinae and Pterostichinae and including a key 281 slug predator, Notonomus gravis Chaudoir, 1865; seven species of staphylinids, and two species 282 of slug (see Table 2 for broader classifications). Prior to the increased rate of chlorpyrifos 283 application, the initial winter samples at crop emergence in July 2005 were the lowest in species 284 richness, this contrasts to the October 2005 spring sample yielding the highest species richness.

285 This large amount of seasonal variation in community composition is further highlighted by the 286 first 2006 sample yielding low species richness again (Figure 2a). Importantly richness through

287 time suggests there was no difference between treatments for the first three sampling points, 288 supporting the rationale behind increasing the chlorpyrifos application rate. Species turnover was 289 high and similar across treatments (65-80\%) for the samples prior to the rate increase of 290 chlorpyrifos, again reflecting the seasonal nature of the species examined (Figure $2 \mathrm{~b}$ ). After the 
291 chlorpyrifos concentration was increased in 2006, species richness diverged between treatments

292 (Figure 2a), with chlorpyrifos having the highest richness in the spring 2006 sampling, before the

293 lowest in the winter 2007 sample. The methidathion treatment had a higher richness than the

294 control and chlorpyrifos in the last two sampling time points. Species turnover began to differ

295 between treatments following the increase in chlorpyrifos, and is much more variable in the

296 chlorpyrifos treatment than the control or methidathion. Over the course of the entire experiment,

297 the mean rank shift pattern reflects richness and turnover, and suggests that variability between

298 treatments for the abundance of different species becomes increased through time, compared to

299 the control (Figure 2c).

300

301 To display how key species from the PRC and multiple GLM analyses (see below) changed in 302 abundance patterns through the trial, we plotted the temporal abundance per treatment for slugs

303 and their potential predators, carabids and staphylinids, as well as other species displaying large

304 responses: earth mites and earwigs (Figure 3). Outside the summer samples in 2006 and 2007

305 (reflecting their seasonality due to lack of moisture post crop harvest), slugs were consistently

306 more abundant in the chlorpyrifos treatment than the control and methidathion. This is in

307 contrast to other pest species such as earth mites and earwigs, which display lower abundance in

308 the organophosphate treatments, especially towards the end of the trial (Figure 3). While some of

309 the slug abundance patterns may be explained by less mortality from predators, the response of

310 the main predator groups (in this dataset) is complex. The carabids initially show quite high

311 abundance, but then for July 2006 and June 2007, carabid numbers in the chlorpyrifos treatment

312 are well below the control and methidathion treatments. After the 2006 pesticide application

313 (including the higher rate) carabids are absent in the chlorpyrifos treatment, though there are

314 only a few individuals in the methidathion and control treatments. Carabid numbers recover and

315 increase from this point, possibly responding to the high abundance of slugs, until the 2007

316 pesticide application: following this event the carabids are reduced again to zero in the

317 chlorpyrifos treatment, whilst persisting in the methidathion and the control treatments. The

318 staphylinids were heavily reduced in numbers in the chlorpyrifos treatment (and methidathion

319 but not to as great extent) following the 2006 pesticide application.

320 The natural enemy community initially displayed an increase over the control as shown by the

321 principal response curve (Figure 4a). In 2006 the effect switches to become negative, and for 
322 methidathion it stays negative. Chlorpyrifos, however, goes back to a positive effect at the final

323 time point. The carabids are strongly weighted against the community trend, indicating that they

324 likely had fewer numbers in the chlorpyrifos treatment by the end of the study period. Predatory

325 bugs also do not follow the treatment effects on the community patterns. For the pests PRC

326 (Figure 4b), there was no differences between the control and chlorpyrifos or methidathion for

327 the initial applications. Target pests (earwigs, earth mites and millipedes) all exhibit strong

328 positive weightings to the negative effect of the pesticide applications, in particular chlorpyrifos

329 for earwigs and earth mites, methidathion for millipedes (Figure 4b). Unlike the target pests,

330 slugs show an opposite trend towards the temporal pest community response (Figure $4 b$ ).

331 The multiple GLM approach broadly agrees with the results from the PRC, as reflected in

332 significant $(P<0.05)$ and non-significant $(P>0.05)$ community differences at most of the same

333 sampling periods. The exception is that for the pest community, the GLM approach determined

334 the July 2005 and September 2006 samplings as significantly different from the control, with the

335 PRC not significant at the 0.05 level (0.077 and 0.087 , respectively). For both the natural

336 enemies and pests, the community was significantly affected following the increase in the rate of

337 chlorpyrifos (After July 2006, Table 3). The carabids and staphylinids showed the largest

338 contributions to the overall community trends, with 23.7 and $13.4 \%$, respectively (Figure 5c).

339 The carabids were significantly affected in September 2006 and June 2007 (Table 3), whereas

340 the staphylinids in July 2006 (Table 3). Other species, such as the predatory bugs (June 2007)

341 and ground dwelling wasps (July 2006) also display significant effect sizes following the spray

342 events (Figure 5c; Table 3). The multiple GLMs on the pest community indicates that effect

343 sizes were also greatest following the spray events (Fig 6a), especially for chlorpyrifos (Fig 6b).

344 Overall, the pest community in all but two samples (both prior to increased rate of chlorpyrifos)

345 was significantly affected by pesticide application (Table 3). The effect sizes also appear to

346 increase with time, but this may also be due to the final crop in the rotation being canola, where

347 mites, aphids and earwigs were all significantly affected by the organophosphate treatments. The

348 earwigs and isopods (slaters) had the largest contributions across the trial (16.5 and 12.2\%,

349 respectively; Figure 6c), but this also appears mostly to be due to the last sample being in the

350 canola phase. Interestingly, the abundance of isopods (slaters) was higher in the chlorpyrifos

351 treatment for the final sample. Weevils, millipedes and orthopterans also provided contributions

352 between 10-11\% each (Figure 6c). While most of these pests displayed negative abundances and 
353 larger effect sizes following a spray event, the effect size for the slugs is greatest in September

354 2006, when there was high abundance in the chlorpyrifos.

355

356 There was a large amount of spatial variation in the yield in the areas of the field corresponding

357 to the difference treatments, and this was further complicated due to an interaction with the block

358 (Figure 7). For the barley (2004 crop) yield, harvested in 2005, there was an overall treatment

359 effect $\left(\chi_{2}^{2}=7.15, p<0.03\right.$ ), but this appears due to block 3 (yield in the Control was

360 significantly lower than yield in both treatments). Following this, there was a significant block

361 effect $\left(\chi^{2}{ }_{2}=10.44, p<0.001\right)$ and significant interaction between the treatments and the block

$362\left(\chi^{2}{ }_{4}=14.32, p<0.001\right)$ (Fig. 7). Following an increase in the rate of chlorpyrifos, for the wheat

363 (2005 crop) yield harvested in 2006 the overall treatment effect was significant $\left(\chi^{2}{ }_{2}=43.38, p<\right.$

364 0.001) with yield significantly higher in the chlorpyrifos treatment than the control in blocks 1

365 and 3 , but lower in block 2 (all significant, $p<0.001$ ). Methidathion yielded significantly lower

366 than the control and chlorpyrifos in blocks 1 and $3(p<0.05)$, and significantly higher than

367 chlorpyrifos in block $2(p<0.001)$. These differences gave an overall significant block effect $\left(\chi^{2}{ }_{2}\right.$

$368=96.99, p<0.001)$ and a significant overall interaction effect $\left(\chi_{4}^{2}=162.90, p<0.001\right)$ (Fig. 7).

369 For the wheat (2006 crop) harvested in 2007, the chlorpyrifos gave consistently higher yields

370 than the control and methidathion in blocks 1 and $3(p<0.01)$, and there was a significant overall

371 Treatment effect $\left(\chi_{2}^{2}=65.19, p<0.001\right)$. There was no significant difference between all

372 treatments in block 2 . The control and methidathion were only significantly different from one

373 another in block 1. Again, there was a significant block effect $\left(\chi^{2}{ }_{2}=37.10, p<0.001\right)$ and a

374 significant overall interaction $\left(\chi_{4}^{2}=40.99, p<0.001\right)$ (Fig. 7). Finally, for the canola yield

375 harvested in 2008 , there was no data in blocks 1 and 2 as seedlings were completely lost due to

376 slug herbivory at establishment (July 2007), regardless of the treatments (i.e. the treated areas

377 still suffered the same damage). In the remaining block (3), chlorpyrifos (at the higher

378 application rate) was significantly lower in yield than the control and methidathion treatment ( $p$

$379<0.001)$ and there was an overall significant treatment effect $\left(\chi^{2}{ }_{2}=56.91, p<0.001\right)$ (Fig. 7).

380

381 Discussion

382 Although the overall interactions of season, pesticide application and crop type on both pest and

383 natural enemy communities are complex (e.g. Brust et al., 1985; Holland \& Luff, 2000), this 
384 study provides some indication of how crop rotation can interact with pesticide use. Importantly,

385 community composition was very similar to the control with standard rates of pesticides,

386 however after higher rates were used, the change in community composition was marked. We

387 demonstrated that such pesticide applications are likely to come with trade-offs associated with

388 the reduction in important generalist predatory species, and that the timing of these reductions

389 may have profound effects on pest suppression and crop production.

390

391 Not all invertebrates will be directly affected by organophosphates in the field, but disruption of

392 important predators at critical times (e.g. a certain crop type) may be more consequential to pest

393 suppression than overall community effects. The final rotation into canola here demonstrates

394 how the reduction of carabids at this point was more detrimental to the grower than the

395 reductions of either carabids and staphylinids in the prior wheat rotations, and the subsequent

396 outbreak of slugs in the increased chlorpyrifos treatment appears indicative of a secondary

397 outbreak. Whilst it is difficult to draw a causal link between absence of predators and the

398 outbreak of slugs in this study, the reduction of slugs by carabids has been demonstrated in

399 similar systems (Nash 2008b). Our results provide an interesting contrast to a recent study that

400 reported that imidacloprid applications increased slug issues due to disruption of adequate

401 biological control as non-target effects (Douglas et al., 2015). Such field response data are

402 important, as there are few studies that use field evaluation of non-target effects of pesticides

403 (e.g. Stäubliet al., 1984; Thomson \& Hoffmann, 2006; Jenkins et al., 2013), most studies

404 typically use laboratory bioassays, or short-term small-plot trials (e.g. Macfadyen et al., 2012;

405 Macfadyen et al., 2014). Further testing of acute and sub-lethal effects under semi-field

406 conditions is required to test our findings, and like Jenkins et al. (2013) we suggest that

407 laboratory assessments of toxicity should be extrapolated with caution to the field setting.

409 In Australia, short-term semi-field studies (Jenkins et al., 2013) have suggested that the impacts

410 of chlorpyrifos are not as disruptive to natural enemies as previously thought (Curtis and Horne,

411 1995), however cumulative impacts over longer time periods are considered disruptive in

412 viticulture (Nash 2010) and arable systems (Nash 2008a). The strong negative response of

413 carabids (Pterostichinae) to chlorpyrifos is concordant with overseas data on the closely related

414 Pterostichus melinarius, with slightly higher rates (720g a.i.) being considered harmful (IOBC 
415 rating 3) (Hassan et al., 1988). Lower rates (480 a.i.) have been shown to be less harmful (IOBC

416 2) to the carabid Bembidion sp, in field trials when compared to lab assays (Floate et al., 1989),

417 however toxicity responses vary between studies and methods, ranging from IOBC 2-4

418 (Cockfield \& Potter, 1983; Bale et al., 1992; Turner et al., 1990). There is limited data on

419 methidathion impacts on natural enemies, however it has been considered as very harmful (IOBC

420 4) to green lacewings in semi-field trials (Hassan et al, 1985) and harmful (IOBC 3) to spiders,

421 predatory bugs and green lacewings in the field (Stäubliet al., 1984). We did not find

422 methidathion to cause significant reductions on those taxa, however this may be due to the lower

423 rate applied here (40 g a.i.) compared to a previous field study (120 g a.i.) (Stäubliet al., 1984).

424 The lack of significant population reductions may also be due tothe sampling methods used do

425 not optimally target these natural enemies, or perhaps there was some avoidance of the winter

426 pesticide application due to their activity at later crop stages. Some species may also have higher

427 levels of tolerance to organophosphates, making results for those taxa that were not strongly

428 impacted by pesticides, as relevant as for those that were.

430 Chemical control is the dominant control option for major pests such as earth mites. While target

431 pests in this study were all controlled, there was no discernible yield response warranting

432 application targeting these pests. Within the common earth mite species there are varying

433 susceptibilities to organophosphates, including methidathion: Penthaleus falcatus has a higher

434 tolerance to methidathion than either of P. major, P. tectus or Halotydeus destructor (Umina \&

435 Hoffmann, 1999). Earwigs (including Forficula auricula) are widespread in southern Australian

436 grain systems, and although they are typically considered as sporadic pests (e.g. Murray et al.,

437 2013), their role as a pest or beneficial species is presently unclear. In addition to acute toxicity

438 and high rates of mortality, chlorpyrifos-ethyl has been shown to reduce the predatory behaviour

439 of the earwig F. auricula in orchards (Malagnoux et al., 2015), where they are considered

440 effective biological control agents. The strong response of earwigs to organophosphates suggests

441 that any form of pest suppression service in grains crops could be hampered by the application of

442 harmful organophosphates such as chlorpyrifos. Despite some limited data suggesting

443 moribundity (Kassebaum, 1985), there is little known about the ability of organophosphates to

444 control millipedes, and there are no currently registered chemicals for control in Australian

445 grains. 
447 Undertaking this study over four seasons and different crop rotations gives some indication of 448 the trade-offs and long-term effects of pesticides on the pest species response, and the response 449 of the natural enemy communities that co-occur with them. Most of the key invertebrate species 450 here would have undergone multiple generations during the experiment, which implies that some 451 sublethal effects (e.g. reduced fecundity, survivorship of immature stages, short-term toxicity 452 effects) should have been captured during this experiment. While changing the application rate 453 of chlorpyrifos during the experiment is not ideal from an analysis point of view, it provides a 454 realistic scenario of how growers adjust rates and frequency of application in response to 455 perceived pest threats. The continued use of organophosphates as a default for control of insect 456 pests in Australian grains is perhaps best exemplified by an emergency permit for use of 457 chlorpyrifos and Pirimicarb (APVMA 82792) to control Russian Wheat Aphid (Diuraphis noxia 458 Kurdjumov 1913) in response to its incursion in 2016 (Yazdani et al., 2017).

460 We did not observe spatially consistent yield benefits from applying pesticides, and in canola the 461 application of pesticides did not prevent widespread seedling loss from slugs (in a season with good levels of rainfall for slug populations, Table 1). Furthermore, there was only one instance where the control had significantly lower yield than both the chlorpyrifos and methidathion treatments, and this benefit was not seen across the whole study area (barley 04/05 block 3, Fig. 7). Large spatial variation within the field in the yield response may be related to spatial variation in the abundance of pests and natural enemies. However, given the significant interactions between pesticide treatments and blocks used to control for spatial variation, it is likely that other invertebrate species that we did not record may be involved. The detrimental effects of chlorpyrifos on the key slug predators may be evident from the lower yield seen in the last remaining block of canola during the final year of the study. Unfortunately, having only one block surviving makes it hard to test this pattern further.

472

473 The lack of a spatially consistent yield benefit from the application of organophosphates suggests 474 that growers could limit broad-spectrum pesticide applications without risking any crop losses 475 due to invertebrate pests. This could be achieved through either applying a threshold-based 476 approach to spray decisions, or selectively targeting areas of the field that may be at risk. For $H$. 
477 destructor a recently published study examined thresholds associated with economic crop losses

478 (Arthur et al., 2015), and recommendations for control have called for rotation in the use of

479 chemicals, non-chemical management options and crop rotations (National Insecticide

480 Resistance Management Working Group, 2016). Managing for control failures due to resistance

481 in pests is an important component of grains pest management in Australia, and the risk of

482 secondary outbreaks requires similar attention. As much of Australian grains production includes

483 rotation with other crops, understanding and responding to the risk of secondary pest outbreaks

484 will require growers to manage their pesticide-use across an entire rotation.

485

486 Conclusions

487

488 Demonstrating the long-term effects of organophosphates on the ecology of invertebrate species

489 within Australian grains systems is complex, due to the scale of production, diverse rotation

490 practices, and inter-annual variation of species diversity and abundance. Despite this, there are

491 important points that arise from this experiment conducted across a standard crop rotation.

492 Firstly, the prophylactic use of organophosphates as a management strategy requires

493 understanding of the risks of secondary outbreak in both the current crop and subsequent crops in

494 the rotation. Secondly, quantifying the impact of reactive management strategies (such as

495 increasing pesticide rates) on pest and natural enemy communities will allow growers to make

496 more informed judgements on the risk of disrupting biological control services.

497

498 Acknowledgements

499

500 Eduard Szöcs provided much of the code for the multiple GLM analysis on his blog

501 (https://edild.github.io). Lewis Wilson provided useful comments on a previous version of this

502 manuscript. 
503

504

505

506

507

508

509

510

511

512

513

514

515

516

517

518

519

520

521

522

523

524

525

526

527

528

529

530

531

\section{References}

Altieri MA, Nichols CI. 2004. Biodiversity and Pest Management in Agrosystems, CRC Press, $2^{\text {nd }}$ edition.

Arthur AL, Hoffmann AA, Umina PA. 2015. Challenges in devising economic spray thresholds for a major pest of Australian canola, the redlegged earth mite (Halotydeus destructor). Pest Management Science 71(10):1462-1470

Bale JS, Ekebuisi M, Wright C. 1992. Effect of seed bed preparation, soil structure and release time on the toxicity of a range of grassland pesticides to the carabid beetle Pterostichus melanarius (Ill.) (Col., Carabidae) using a microplot technique. Journal of Applied Entomology 113(1-5): 175-182

Brust GE, Stinner BR, McCartney DA. 1985. Tillage and soil insecticide effects on predatorblack cutworm (Lepidoptera: Noctuidae) interactions in corn agroecosystems. Journal of Economic Entomology 78: 389-1392

Cockfield SD, Potter, DA. 1983. Short-term effects of insecticidal applications on predaceous arthropods and oribatid mites in Kentucky bluegrass turf. Environmental Entomology 12(4): 1260-1264

Curtis JE, Horne, PA. 1995. Effect of chlorpyrifos and cypermethrin applications on non-target invertebrates in a conservation-tillage crop. Australian Journal of Entomology 34:229231

Dormann CF, McPherson JM, Araújo MB, Bivand R, Bolliger J, Carl G, Davies GR, Hirzel A, WA Jetz, Kissling DW, Kühn I, 2007. Methods to account for spatial autocorrelation in the analysis of species distributional data: a review. Ecography 30(5): 609-628

Douglas MR, Rohr, JR, Tooker JF. 2015. Neonicotinoid insecticide travels through a soil food chain, disrupting biological control of non-target pests and decreasing soya bean yield. Journal of Applied Ecology 52(1):250-260

Dutcher JD. 2007. A review of resurgence and replacement causing pest outbreaks in IPM. In General concepts in integrated pest and disease management (pp. 27-43). Springer Netherlands. 
532 Edwards OR, Franzmann B, Thackray D, Micic S. 2008. Insecticide resistance and implications

533

534

535

536

537

538

539

540

541

542

543

544

545

546

547

548

549

550

551

552

553

554

555

556

557

558

559

560

561

562

for future aphid management in Australian grains and pastures: a review. Australian Journal of Experimental Agriculture 48(12): 1523-1530

Floate KD, Elliott RH, Doane JF, Gillott C. 1989. Field bioassay to evaluate contact and residual toxicities of insecticides to carabid beetles (Coleoptera: Carabidae). Journal of Economic Entomology 82(6): 1543-1547Glen DM. 1989. Understanding and predicting slug problems in cereals. In: Henderson IF. (ed.) Slugs and Snails in World Agriculture. Thorton Heath: British Crop Protection Council.

Gu H, Fitt GP, Baker GH. 2007. Invertebrate pests of canola and their management in Australia: a review. Australian Journal of Entomology 46:231-243

Guedes RNC, Smagghe G, Stark JD, Desneux N. 2016. Pesticide-induced stress in arthropod pests for optimized integrated pest management programs. Annual Review of Entomology 61:43-62

Gross K, Rosenheim JA. 2011. Quantifying secondary pest outbreaks in cotton and their monetary cost with causal-inference statistics. Ecological Applications 21(7):2770-2780

Grundy PR, Maelzer D, Collins PJ, Hassan E. 2000. Potential for integrating eleven agricultural insecticides with the predatory bug Pristhesancus plagipennis (Hemiptera: Reduviidae). Journal of Economic Entomology 93:584-589

Hallett LM, Jones SK, MacDonald AAM, Jones MB, Flynn DF, Ripplinger J, Slaughter P, Gries C, Collins SL. 2016. codyn: An R package of community dynamics metrics. Methods in Ecology and Evolution 7(10):1146-1151

Hassan SA. 1985. Standard methods to test the side-effects of pesticides on natural enemies of insects and mites developed by the IOBC/WPRS Working Group 'Pesticides and beneficial organisms'. Bulletin OEPP/EPPO 15:214-255

Hassan SA, Bigler F, Bogenschütz H, Boller E, Brun J, Chiverton P, Edwards P, Mansour F, Naton E, Oomen PA, Overmeer WPJ, Polgar L, Rieckmann W, Samsøe-petersen L, Stäubli A, Sterk G, Tavares K, Tuset JJ, Viggiani G, Vivas AG. 1988. Results of the fourth joint pesticide testing programme by the IOBC/WPRS-Working Group "Pesticides and Beneficial Arthropods". Journal of Applied Entomology 105:321-329

Holland J, Luff M. 2000. The effects of agricultural practices on Carabidae in temperate agroecosystems. Integrated Pest Management Reviews 5:109-129 
563 Isbell RF. 1996. The Australian Soil Classification, Melbourne, CSIRO Publishing.

564 Jenkins S, Hoffmann AA, McColl S, Tsitsilas A, Umina PA. 2013. Synthetic pesticides in agro-

565

566

567

568

569

570

571

572

573

574

575

576

577

578

579

580

581

582

583

584

585

586

587

588

589

590

591 ecosystems: are they as detrimental to nontarget invertebrate fauna as we suspect? Journal of Economic Entomology 106(2):756-75

Kassebaum BJ. 1985. Susceptibility of the black Portuguese millipede, Ommatoilus moreletii Lucas (Diplopoda: Julidae) to insecticides. Thesis (M. Ag. Sc.), University of Adelaide, South Australian Department of Agriculture.

Macfadyen S, Zalucki MP. 2012. Assessing the short-term impact of an insecticide (Deltamethrin) on predator and herbivore abundance in soybean glycine max using a replicated small-plot field experiment. Insect Science 19(1):112-20

Macfadyen S, Hardie DC, Fagan L, Stefanova K, Perry KD, DeGraaf HE, Holloway J, Spafford H, Umina PA. 2014. Reducing insecticide use in broad-acre grains production: an Australian study. PloS one 9(2): e89119

Malagnoux L, Capowiez Y, Rault M. 2015. Impact of insecticide exposure on the predation activity of the European earwig Forficula auricularia. Environmental Science and Pollution Research 22(18): 14116-14126

Murray DAH, Clarke MB, Ronning DA. 2013. Estimating invertebrate pest losses in six major Australian grain crops. Australian Journal of Entomology 52:227-241

Naranjo SE. 2005. Long-term assessment of the effects of transgenic Bt cotton on the abundance of nontarget arthropod natural enemies. Environmental Entomology 34(5): 1193-1210

Nash MA, Thomson LJ, Hoffmann AA. 2007. Slug control in Australian canola: monitoring, molluscicidal baits and economic thresholds. Pest Management Science 63(9): 851-859

Nash MA, Thomson LJ, Hoffmann AA. 2008a. Effect of remnant vegetation, pesticides and farm management on abundance of the beneficial predator Notonomus gravis (Chaudoir) (Coleoptera: Carabidae). Biological Control 46:83-93

Nash, MA, Thomson, LJ, Horne, PA, Hoffmann, AA (2008b) Notonomus gravis (Chaudoir) (Coleoptera: Carabidae) predation of Deroceras reticulatum Muller (Gastropoda: Agriolimacidae), an example of fortuitous biological control. Biological Control 47, 328334. 
592 Nash MA, Hoffmann AA, Thomson LJ. 2010. Identifying signature of chemical applications on

593

594

595

596

597

598

599

600

601

602

603

604

605

606

607

608

609

610

611

612

613

614

615

616

617

618

619

620

621 indigenous and invasive nontarget arthropod communities in vineyards. Ecological Applications 20(6):1693-1703

O'Hara RB, Kotze DJ. 2010. Do not log-transform count data. Methods in Ecology \& Evolution 1:118-122

Radcliffe JC. 2002. 'Pesticide Use in Australia.' (Australian Academy of Technological Sciences and Engineering: Melbourne.)

Readshaw JL. 1975. Biological control of orchard mites in Australia with an insecticide-resistant predator. Journal of the Australian Institute of Agricultural Science 41(3): 213-214

Rose R, Dively GP. 2007. Effects of insecticide-treated and lepidopteran-active Bt transgenic sweet corn on the abundance and diversity of arthropods. Environmental Entomology 36(5): 1254-1268

Stark JD, Banks JE, Acheampong S. 2004. Estimating susceptibility of biological control agents to pesticides: influence of life history strategies and population structure. Biological Control 29(3):392-398

Stäubli A, Hächler M, Antonin P, Mittaz C. 1984. Tests de nocivité de divers pesticides envers les ennemis naturels des principaux ravageurs des vergers de poiriers en Suisse romande. Revue Suisse Viticulture Arboriculture Horticulture 16(5):279-286

Steinmann KP, Zhang M, Grant JA. 2011. Does use of pesticides known to harm natural enemies of spider mites (Acari: Tetranychidae) result in increased number of miticide applications? An examination of California walnut orchards. Journal of Economic Entomology 104(5): 1496-1501

Szöcs E, Van den Brink PJ, Lagadic L, Caquet T, Roucaute M, Auber A, Bayona Y, Liess M, Ebke P, Ippolito A, ter Braak CJ, Brock TCM, Schäfer RB. 2015. Analysing chemicalinduced changes in macroinvertebrate communities in aquatic mesocosm experiments: a comparison of methods. Ecotoxicology 24(4):760-769

Thomson LJ, Hoffmann AA. 2006. Field validation of laboratory-derived IOBC toxicity ratings for natural enemies in commercial vineyards. Biological Control 39(3):507-515

Thomson LJ, Hoffmann AA. 2007. Ecologically sustainable chemical recommendations for agricultural pest control? Journal of Economic Entomology 100(6):1741-1750 
622 Turner AS, Bale JS, Clements RO. 1990. Effects of a range of pesticides on the carabid

623

624

625

626

627

628

629

630

631

632

633

634

635

636

637

638

639

640

641

642

643

644

645

646

647

648

649

650

651

beetle Pterostichus melanarius (Ill.) using a microplot technique. Journal of Applied Entomology 109(1-5):463-469

Umina PA, Jenkins S, McColl S, Arthur A, Hoffmann AA. 2015. A framework for identifying selective chemical applications for IPM in dryland agriculture. Insects 6(4): 988-1012

Umina PA, Hoffmann AA. 1999. Tolerance of cryptic species of blue oat mites (Penthaleus spp.) and the redlegged earth mite (Halotydeus destructor) to pesticides. Australian Journal of Experimental Agriculture 39(5):621-628

Valenzuela I, Hoffmann AA. 2015. Effects of aphid feeding and associated virus injury on grain crops in Australia. Austral Entomology 54:292-305

van der Werf HM. 1996. Assessing the impact of pesticides on the environment. Agriculture, Ecosystems \& Environment 60(2-3):81-96.Van den Brink PJ, Ter Braak CJF. 1999. Principal response curves: Analysis of time-dependent multivariate responses of biological community to stress. Environmental Toxicology and Chemistry 18(2):138-148

Wang Y, Naumann U, Wright ST, Warton DI. 2012. mvabund-an R package for model-based analysis of multivariate abundance data. Methods in Ecology and Evolution 3(3):471-474

Whitehouse MA, Wilson LJ, Fitt GP. 2005. A comparison of arthropod communities in transgenic Bt and conventional cotton in Australia. Environmental Entomology 34(5):1224-1241

Wiles JA, Jepson PC. 1995. Dosage reduction to improve the selectivity of deltamethrin between aphids and coccinellids in cereals. Entomologia Experimentalis et Applicata 76(1):83-96

Wilson LJ, Bauer LR, Lally DA. 1998. Effect of early season insecticide use on predators and outbreaks of spider mites (Acari: Tetranychidae) in cotton. Bulletin of Entomological Research 88(4):477-488

Wilson LJ, Bauer LR, Lally DA. 1999. Insecticide-induced increases in aphid abundance in cotton. Austral Entomology 38(3):242-243

Yazdani M, Baker G, DeGraaf H, Henry K, Hill K, Kimber B, Malipatil M, Perry K, Valenzuela I, Nash MA. 2017. First detection of Russian wheat aphid Diuraphis noxia Kurdjumov (Hemiptera: Aphididae) in Australia: a major threat to cereal production. Austral Entomology doi: 10.1111/aen.12292 
652 Zeilinger AR, Olson DM, Andow DA. 2016. Competitive release and outbreaks of non-target 653 pests associated with transgenic Bt cotton. Ecological Applications 26(4):1047-1054 


\section{Table $\mathbf{1}$ (on next page)}

Sowing dates, seasonal and experimental conditions throughout the study period at the experimental site near Mortlake in Victoria.

*Very delayed sowing this season due to seasonal conditions. The yield for Kellalac from Hamilton National Variety Trials for each season is included, as is the site mean for Triazene Tolerant canola varieties for comparative purposes as obtained from relevant trial reports ( http://www.farmtrials.com.au/trial_report_library.php?action=search\&query=Hamilton accessed 13 Feb 2017). 


\begin{tabular}{|c|c|c|c|c|}
\hline & Crop sown & $\begin{array}{c}\text { Planting date } \\
\text { (treatments applied) }\end{array}$ & $\begin{array}{c}\text { Growing season } \\
\text { rainfall } \\
(\mathrm{mm})\end{array}$ & $\begin{array}{l}\text { Average } \\
\text { yield in } \\
\text { region t/ha }\end{array}$ \\
\hline 2004 & Barley (Gardner) & $\begin{array}{c}* 15 \text { Oct } 2004 \\
(19 \text { Oct })\end{array}$ & Sep-Feb 310 & $\begin{array}{l}\text { Wheat } 2.06 \\
\text { Canola } 1.05\end{array}$ \\
\hline 2005 & Wheat (Kellalac) & $\begin{array}{c}28 \text { Jun } 2005 \\
(1 \mathrm{Jul})\end{array}$ & Apr-Nov 348 & $\begin{array}{l}\text { Wheat } 2.67 \\
\text { Canola } 2.31\end{array}$ \\
\hline 2006 & Wheat (Kellalac) & $\begin{array}{c}17 \text { Jun } 2006 \\
\text { (21 Jun) }\end{array}$ & Apr-Nov 269 & $\begin{array}{l}\text { Wheat } 2.75 \\
\text { Canola } 1.7\end{array}$ \\
\hline 2007 & $\begin{array}{c}\text { Canola (Thunder TT } \\
\text { Pacific seeds) }\end{array}$ & $\begin{array}{c}5 \text { June } 2007 \\
\text { (6 Jun) }\end{array}$ & Apr-Nov 470 & $\begin{array}{l}\text { Wheat } 5.37 \\
\text { Canola } 2.65\end{array}$ \\
\hline
\end{tabular}




\section{Table 2 (on next page)}

Natural enemy and pest communities and taxa defined for this study.

IOBC (International Organization for Biological and Integrated Control Pesticides and Beneficial Organisms) ratings for representative members of each beneficial group are included, as well as which target pests are registered for the respective chemical use in Australia. An empty cell indicates no available information. IOBC ratings for the natural enemies are taken for a representative from that grouping. IOBC toxicity ratings are on a 4 point scale ( 1 "harmless" $<25 \%$ mortality to 4 "very harmful" $>75 \%$ ). The registration for pests is taken from the chemical labels for the respective pesticides (Lorsban (chlorpyrifos), Dow Chemicals, APVMA Approval No: 32887/56655; Supracide (methidathion), Syngenta, APVMA Approval No: 33041/5). Registration is marked (Y)es if the target pest is included for grains crops, if there is registration for a target pest outside of grains, it is included in parentheses. 


\section{Natural Enemies}

\begin{tabular}{|c|c|c|c|c|}
\hline Group & Includes & Chlorpyrifos & Methidathion & Total \\
\hline lacewings & Micromus tasmaniae & 4 & 4 & 61 \\
\hline carabids & Coleoptera: Carabidae & $2-4$ & & 413 \\
\hline staphylinids & Coleoptera: Staphylinidae & $3-4$ & & 414 \\
\hline ladybirds & Coleoptera: Coccinellidae & $3-4$ & & 14 \\
\hline wasps & all hymenopteran parasitoids & $1 \& 4$ & & 144 \\
\hline predatory bugs & $\begin{array}{l}\text { predatory bugs, e.g. assassin bugs } \\
\text { hunting Spiders (Lycosidae, }\end{array}$ & 4 & 3 & 96 \\
\hline spider1 & $\begin{array}{l}\text { Miturgidae, Lamponidae } \\
\text { web-building spiders and harvestmen }\end{array}$ & 3 & & 493 \\
\hline spider2 & (Linyphiidae, Opiliones) & & 3 & 182 \\
\hline & sac-spiders (Clubionidae, & & & \\
\hline spider3 & Gnaphosidae, Corinnidae) & & & 96 \\
\hline salticids & jumping spiders (Salticidae) & & & 18 \\
\hline predatory mites & $\begin{array}{l}\text { snout mites, mesotig mites, } \\
\text { trombididae mites }\end{array}$ & 4 & & 225 \\
\hline syrphids & hoverflies & & & 70 \\
\hline centipedes & all centipedes & & & 7 \\
\hline
\end{tabular}

\section{Pests}

\begin{tabular}{|c|c|c|c|c|}
\hline Group & Includes & $\begin{array}{l}\text { Registered - } \\
\text { Chlorpyrifos }\end{array}$ & $\begin{array}{l}\text { Registered - } \\
\text { Methidathion }\end{array}$ & \\
\hline slaters & Isopoda: Armadillidiidae & & & 1745 \\
\hline & Ommatoiulus moreleti (Portuguese & & & \\
\hline millipedes & millipedes) & & & 960 \\
\hline slugs & $\begin{array}{l}\text { Milax gagates, Deroceras reticulatum } \\
\text { predominantly Forficula auricula, }\end{array}$ & & & 305 \\
\hline earwigs & some natives & (Stonefruit) & & 1280 \\
\hline & Halotydeus destructor, Penthaleus & & & \\
\hline earth mites & spp., Balaustium spp. & Y & $\mathrm{Y}$ & 159 \\
\hline aphids & $\begin{array}{l}\text { Rhopalosiphum padi, Myzus persicae } \\
\text { Sminthurus viridis (Collembola: }\end{array}$ & Y & $\begin{array}{l}\text { (Lucerne, } \\
\text { Lupins etc.) }\end{array}$ & 3349 \\
\hline lucerne flea & Sminthuridae) & & (Lucerne) & 23 \\
\hline scarab beetles & Coleoptera: Scarabidae & $\mathrm{Y}$ & (Pasture) & 165 \\
\hline lepidopterans & pest catepillars & $\mathrm{Y}$ & & 82 \\
\hline weevils & Coleoptera: Curculonidae & $\mathrm{Y}$ & (Lucerne) & 556 \\
\hline orthopterans & crickets and grasshoppers & $\mathrm{Y}$ & (Ornamentals) & 625 \\
\hline
\end{tabular}




\section{Table 3 (on next page)}

Significance of treatments from Principal Response Curve (PRC) and multiple GLM analyses for the beneficial and pest communities, at each sampling time.

The PRC analysis score is for the whole community and reflects the redundancy analysis (RDA) score for that single time point. The GLM scores are for significance of the community or species deviance related to the treatments at each sampling time. All bold values indicate significant score $(p<0.05)$ 
Beneficial community

Community

\begin{tabular}{rrccc}
\multicolumn{1}{c}{ Year } & Month & $\begin{array}{c}\text { RDA } \\
\text { (PRC) }\end{array}$ & GLM & lacewings \\
2005 & July & 0.571 & 0.442 & 1.000 \\
& October & 0.697 & 0.515 & 0.930 \\
2006 & March & 0.695 & 0.312 & 1.000 \\
& July & $\mathbf{0 . 0 0 1}$ & $\mathbf{0 . 0 0 0}$ & 1.000 \\
& October & $\mathbf{0 . 0 0 1}$ & $\mathbf{0 . 0 0 2}$ & 0.057 \\
2007 & March & 0.272 & 0.374 & 1.000 \\
& June & $\mathbf{0 . 0 0 1}$ & $\mathbf{0 . 0 0 0}$ & 1.000
\end{tabular}

Pest community

Community

RDA
Year Month

2005 July $0.067 \quad \mathbf{0 . 0 2 8}$

2006 March 0.859

0.713

$\begin{array}{lll}\text { July } & \mathbf{0 . 0 2 8} & \mathbf{0 . 0 2 5}\end{array}$

October $\quad 0.087 \quad \mathbf{0 . 0 1 1}$

2007 March $\mathbf{0 . 0 0 3} \mathbf{0 . 0 0 6}$

June $\mathbf{0 . 0 0 4} \quad \mathbf{0 . 0 0 0}$

slaters
0.230
0.733
0.946
0.446
0.495
0.346
$\mathbf{0 . 0 1 7}$

predatory

Groups

$\begin{array}{lcccccccccccc}\text { wasps } & \text { carabids } & \text { staphylinids } & \text { predatory } & \text { mites } & \text { ladybirds } & \text { syrphids } & \text { centipedes } & \text { spider1 } & \text { spider2 } & \text { spider3 } & \text { salticids } & \text { predatory bugs } \\ 1.000 & 0.937 & 0.639 & 1.000 & 1.000 & 1.000 & 1.000 & 0.639 & 1.000 & 1.000 & 0.639 & 1.000 \\ 0.866 & 0.975 & 0.991 & 0.991 & 0.796 & 0.929 & 0.983 & 0.991 & 0.974 & 0.983 & 0.991 & 0.783 \\ 0.997 & 0.997 & 0.068 & 0.997 & 1.000 & 1.000 & 0.633 & 0.733 & 0.997 & 1.000 & 1.000 & 0.984 \\ \mathbf{0 . 0 0 9} & 0.088 & \mathbf{0 . 0 3 8} & \mathbf{0 . 0 2 1} & 1.000 & 1.000 & 0.547 & 0.547 & 1.000 & 1.000 & 1.000 & 1.000 \\ 0.648 & \mathbf{0 . 0 4 2} & 0.195 & 1.000 & 0.648 & 0.271 & 0.648 & 0.648 & 0.648 & 0.648 & 0.648 & 0.951 \\ 0.818 & 0.865 & 0.818 & 0.721 & 1.000 & 1.000 & 1.000 & 0.865 & 0.818 & 0.721 & 1.000 & 0.865 \\ 0.732 & \mathbf{0 . 0 0 1} & 0.933 & 0.933 & 1.000 & 1.000 & 0.885 & 0.933 & 0.227 & 0.826 & 1.000 & \mathbf{0 . 0 1 9}\end{array}$

\begin{tabular}{|c|c|c|c|c|c|c|c|c|c|}
\hline \multirow[b]{2}{*}{ millipedes } & \multicolumn{6}{|c|}{ Groups } & \multirow[b]{2}{*}{ lepidopterans } & \multirow[b]{2}{*}{ weevils } & \multirow[b]{2}{*}{ orthopterans } \\
\hline & slugs & earth mites & $\begin{array}{l}\text { lucerne } \\
\text { flea }\end{array}$ & aphids & earwigs & $\begin{array}{l}\text { scarab } \\
\text { beetles }\end{array}$ & & & \\
\hline 0.230 & 0.968 & 1.000 & 1.000 & 1.000 & 0.968 & 0.069 & 1.000 & 0.656 & 0.643 \\
\hline 0.707 & 0.579 & 1.000 & 0.274 & 0.948 & 0.974 & 0.961 & 0.809 & 0.961 & 0.529 \\
\hline 0.976 & 1.000 & 1.000 & 1.000 & 1.000 & 0.976 & 0.976 & 0.976 & 0.976 & 0.577 \\
\hline 0.500 & 0.446 & 0.579 & 1.000 & 1.000 & 0.108 & 0.749 & 1.000 & 0.500 & 0.617 \\
\hline 0.421 & 0.038 & 1.000 & 1.000 & 1.000 & 0.116 & 0.221 & 1.000 & 1.000 & 0.274 \\
\hline 0.346 & 1.000 & 1.000 & 1.000 & 1.000 & 0.555 & 0.555 & 0.656 & 0.007 & 0.285 \\
\hline 0.703 & 0.703 & 0.018 & 1.000 & 0.027 & 0.005 & 1.000 & 0.059 & 0.426 & 0.703 \\
\hline
\end{tabular}


Figure 1

Site layout

Site layout indicating insecticide treatments and invertebrate sampling transects (blocks) in relation to overall yield from the 36 ha field (pooled data from 2003-2007).

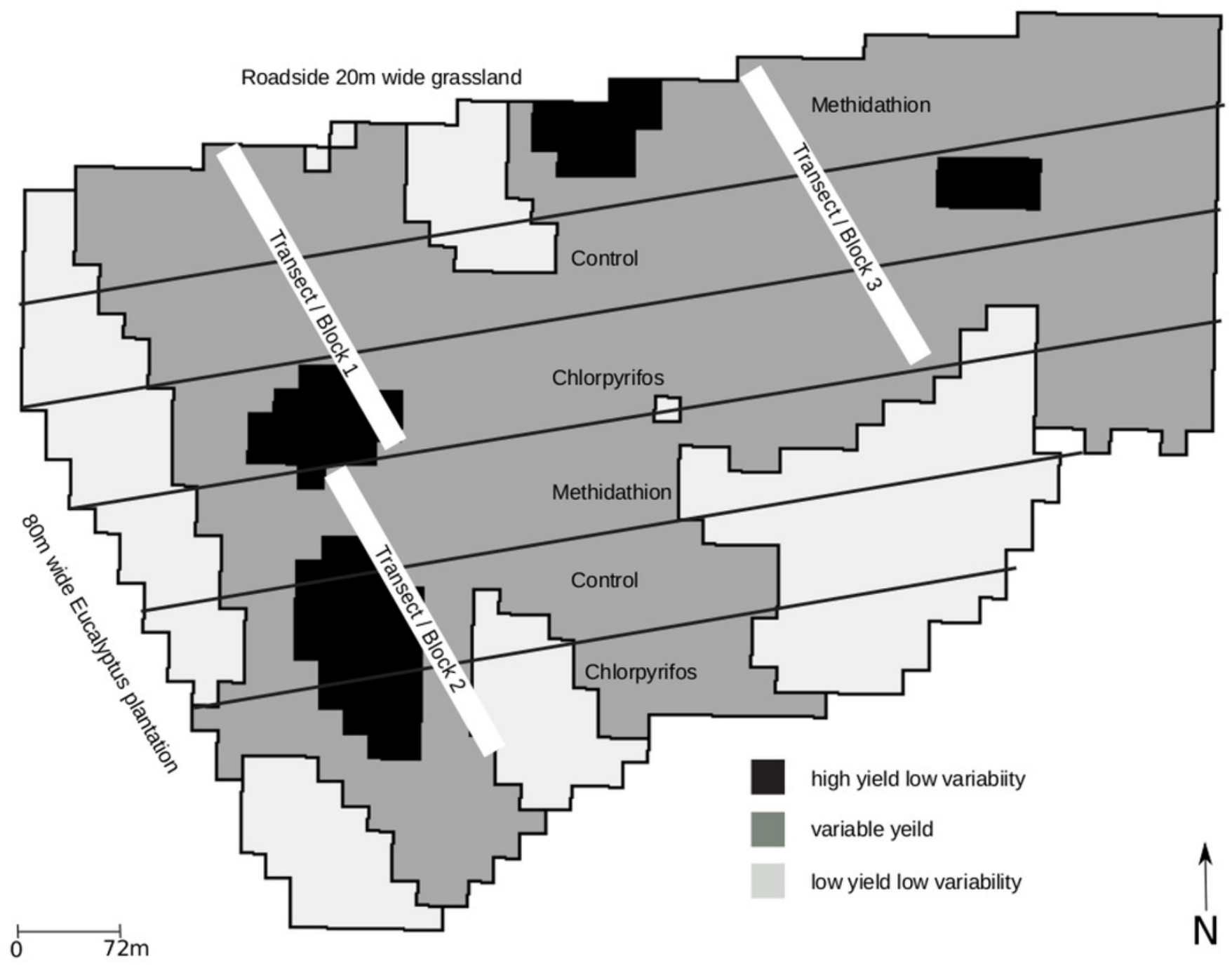


Figure 2 (on next page)

Species richness

(a) Change in total species richness over time, total of 115 taxa. The grey bars represent the sampling times and the red dashed lines represent the application of pesticides associated with each treatment. (b) Total proportional species turnover for each time point through the study period. (c) Mean rank shifts. Note for $b$ and $c$ the initial sampling and spray event is not present, as each point represents the change from the previous sampling event. The first spray event is immediately before the beginning of these panels, however. 

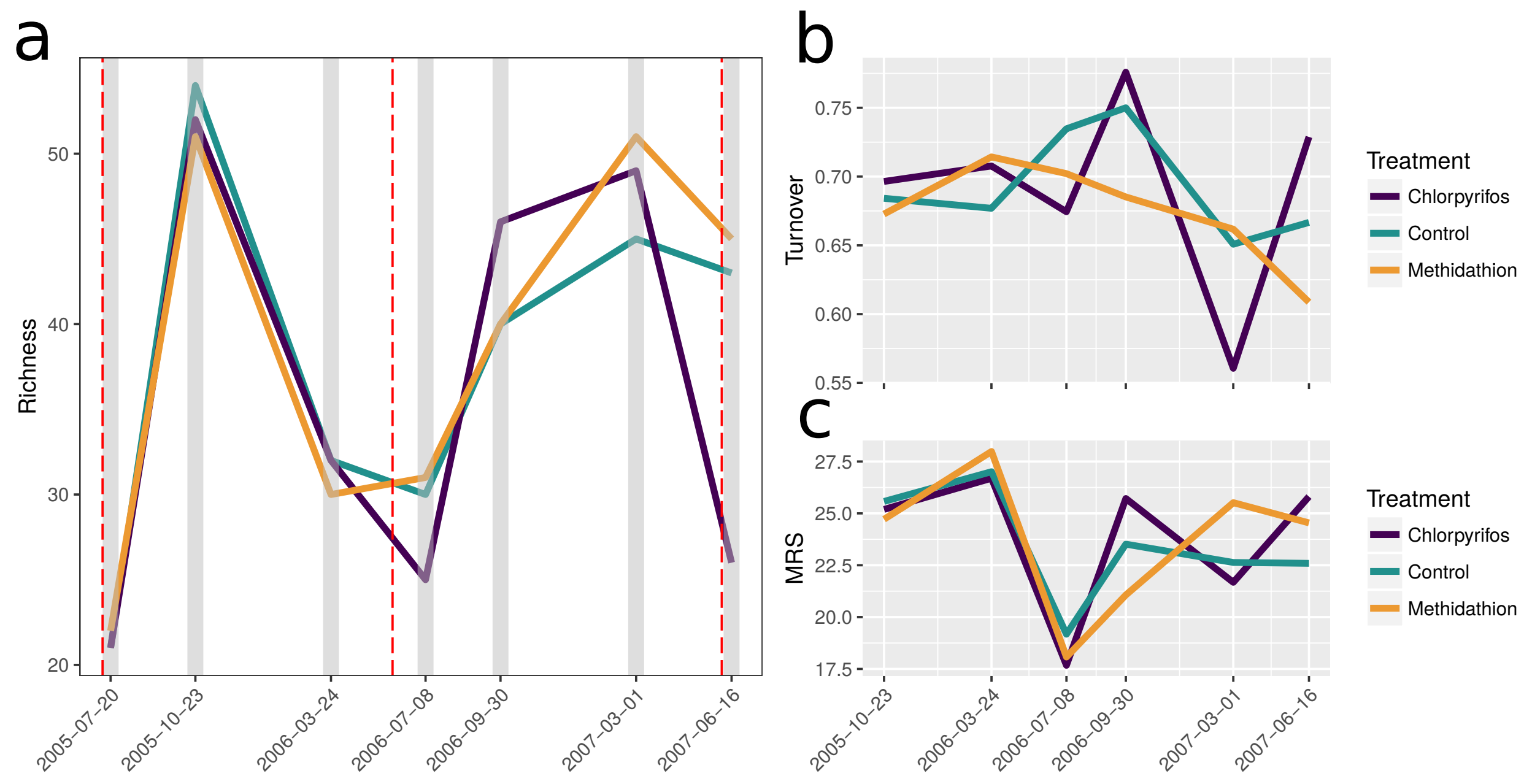


\section{Figure 3 (on next page)}

Selected species abundances

Abundances (untransformed count data) through time for selected pests and natural enemies displaying important responses in the analyses (See Figures 4-6 and Table 3). Pests (a) slugs, (b) earth mites and (c) earwigs, and the predatory beetles: (d) carabids and (e) staphylinids. 


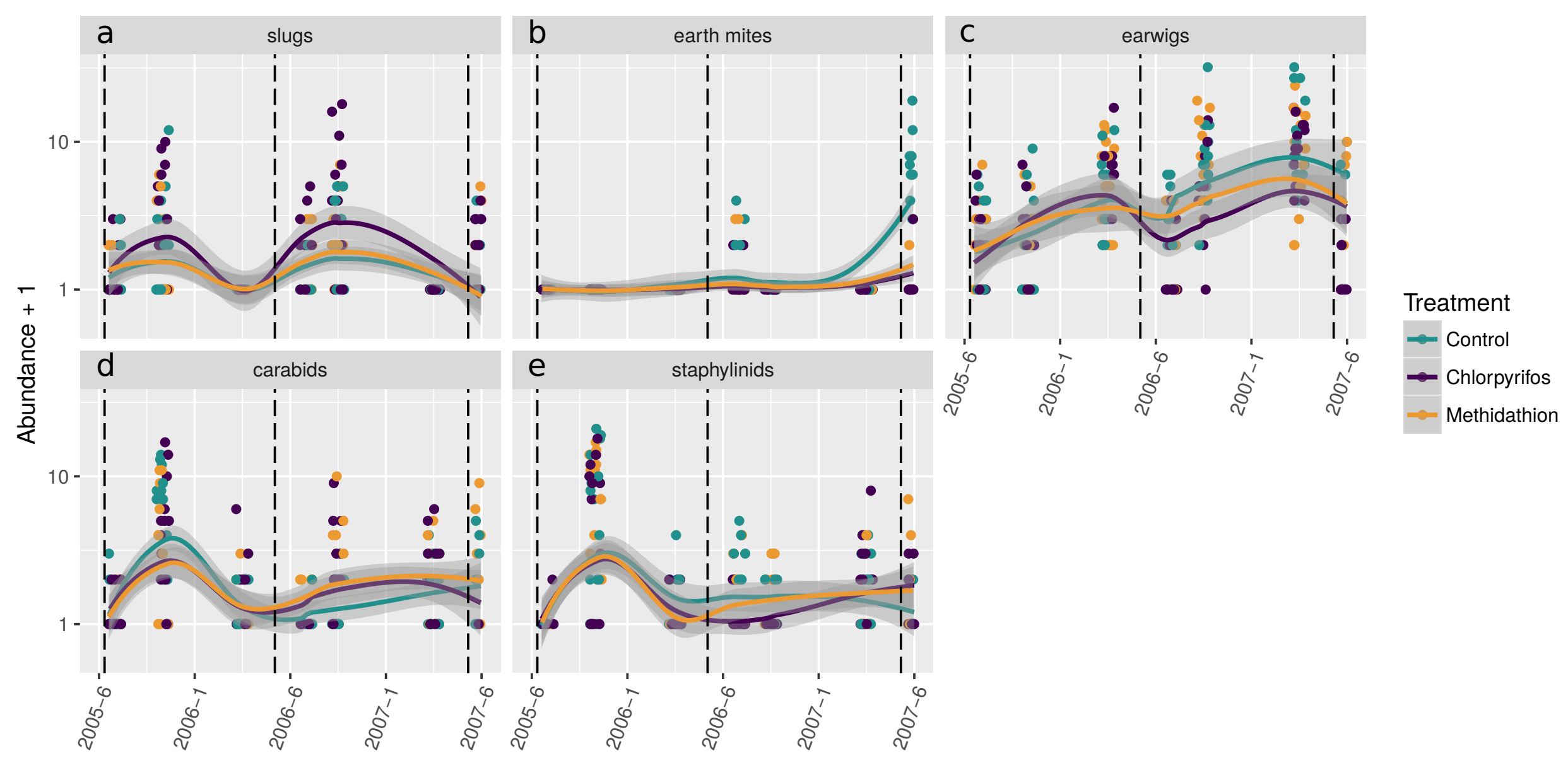


Figure 4 (on next page)

Principal response curves

(a) Principal response curve for the natural enemy community. The left y-axis shows the Effect size. The position on the right $y$-axis reflects the weighting of the species to the overall response. The 0 line reflects the untreated control. (b) Principal response curve for the pest community. The left $y$-axis dhows the Effect size. The position on the right $y$-axis reflects the weighting of the species to the overall response. The 0 line reflects the untreated control. 

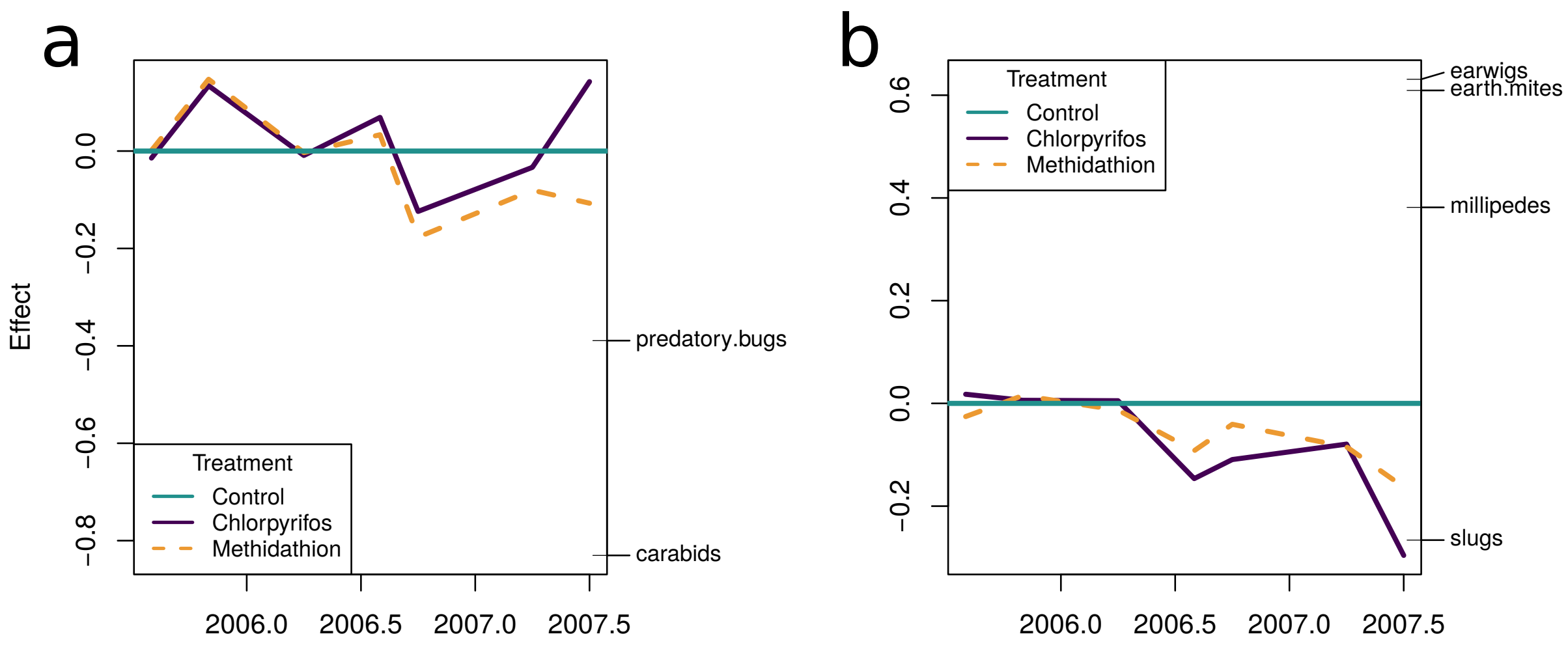


\section{Figure $\mathbf{5}$ (on next page)}

Beneficial community

Effect size through time on the natural enemy community identified in this study. Each species grouping has had individual generalised linear models performed on abundance. The effect size is relative to the control, and the different colours represent the species contribution to that effect size, at that point in time. The dashed vertical lines represent the application of the pesticide treatments. (b) The overall community response to the application of the treatments through time. For both $a$ and $b$, the control is represented by the 0 line, and the treatments correspond to the deviance from the control. The three dashed vertical lines represent the application of the pesticide treatments. (c) The proportional contribution of each species to the overall deviance. 
PeerJ

\section{Manuscript to be reviewed}

a
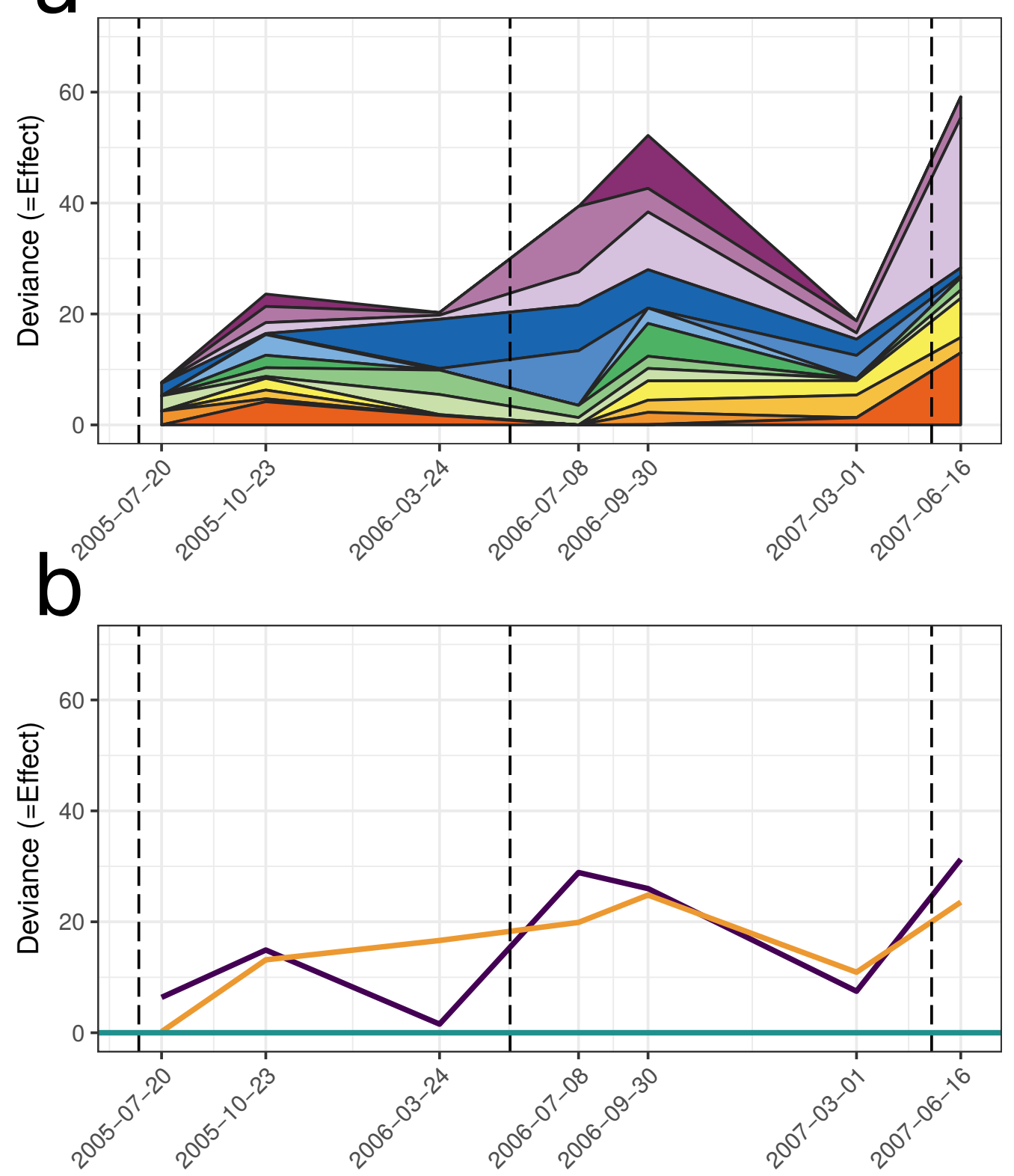

C

Natural Enemies

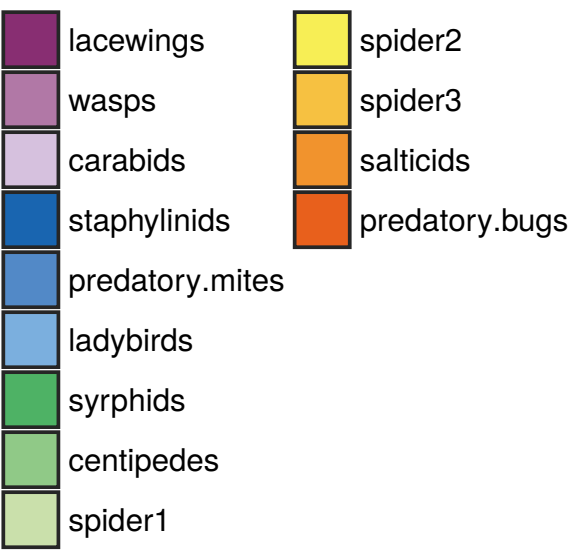

Treatment

- Chlorpyrifos

- Methidathion

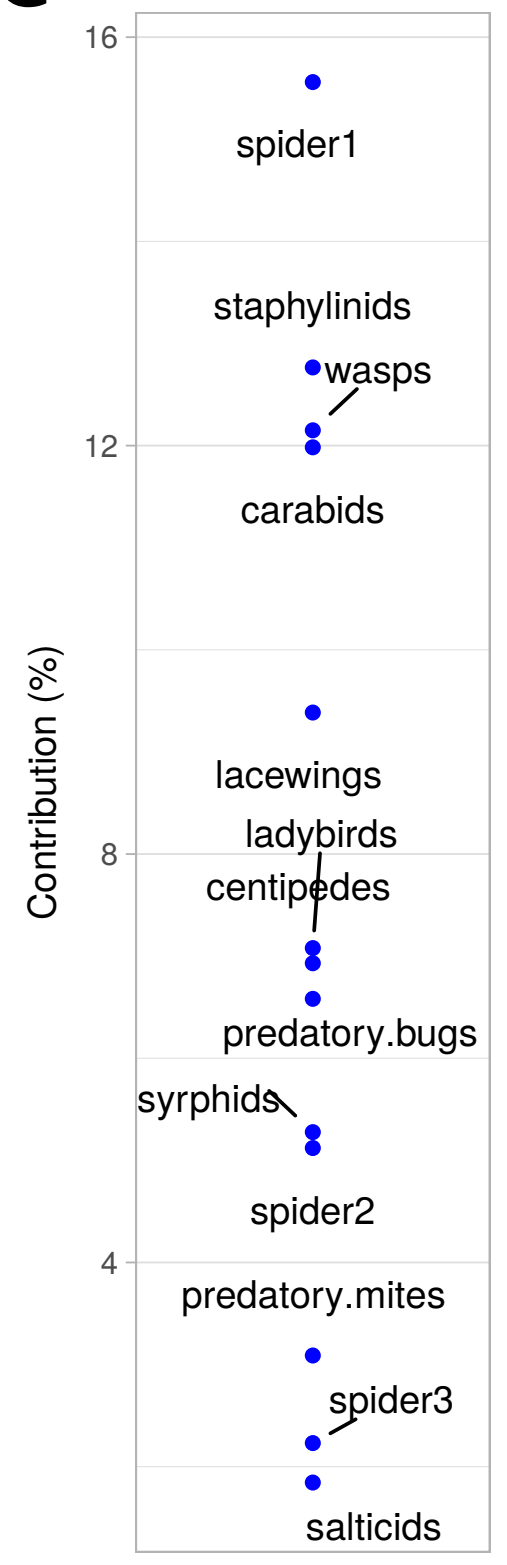




\section{Figure 6 (on next page)}

\section{Pest community}

Effect size through time on the pest community identified in this study. (a) Each species grouping has had individual generalised linear models performed on abundance. The effect size is relative to the control, and the different colours represent the species contribution to that effect size, at that point in time. The three dashed vertical lines represent the application of the pesticide treatments. (b) The overall community response to the application of the treatments through time. The control is represented by the 0 line, and the treatments correspond to the deviance from the control. The four dashed vertical lines represent the application of the pesticide treatments. (c) The proportional contribution of each species to the overall deviance. 
a
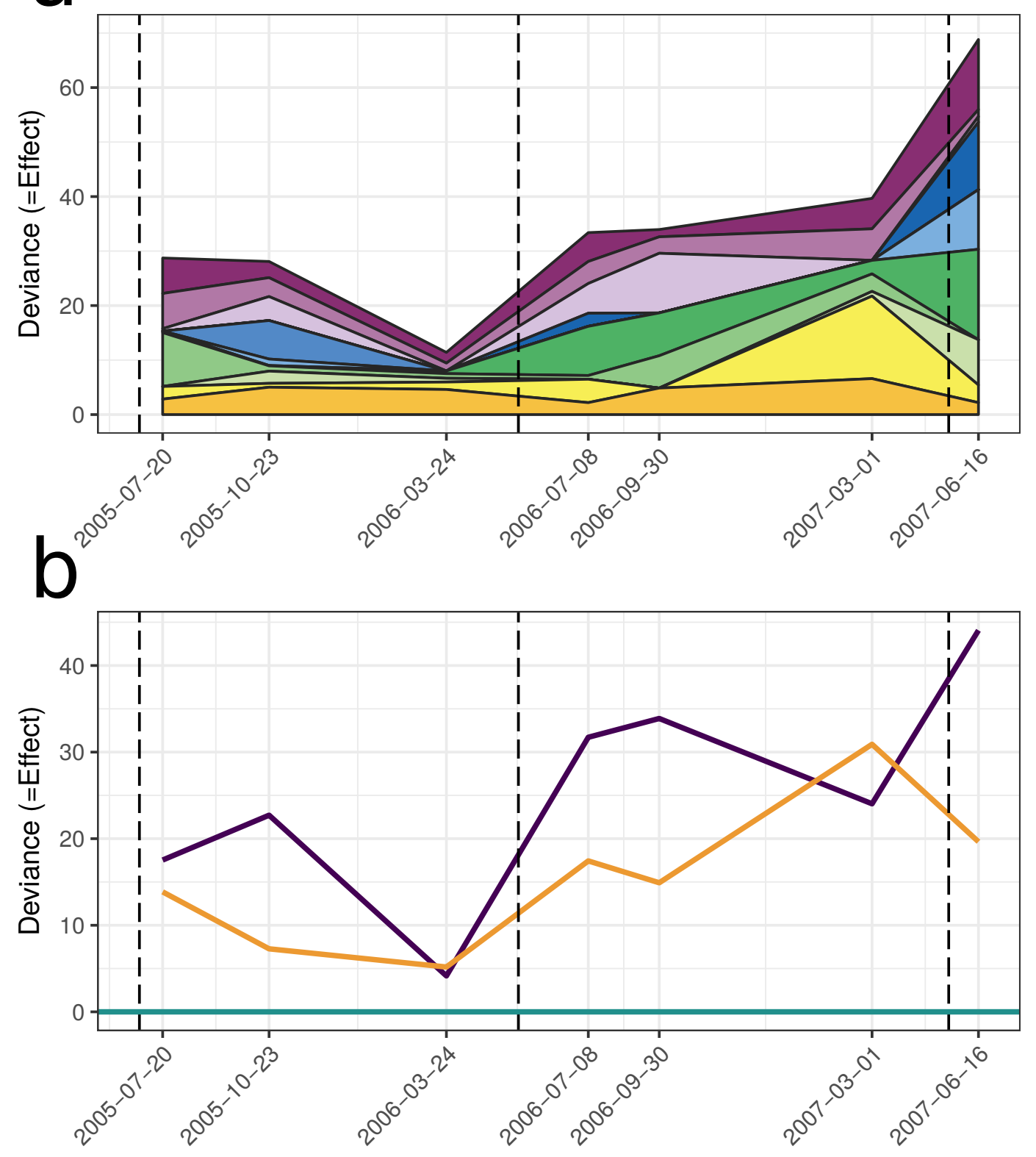

C

Pest species

\begin{tabular}{ll}
$\square$ & slaters \\
millipedes \\
slugs \\
\hline$\square$ \\
earth.mites \\
\hline$\square$ lucerne.flea \\
\hline$\square$ aphids \\
\hline$\square$ earwigs \\
scarab.beetles \\
\hline$\square$ lepidopterans
\end{tabular}

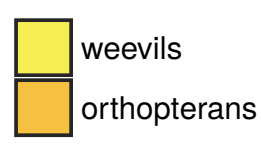

Treatment

- Chlorpyrifos

- Methidathion

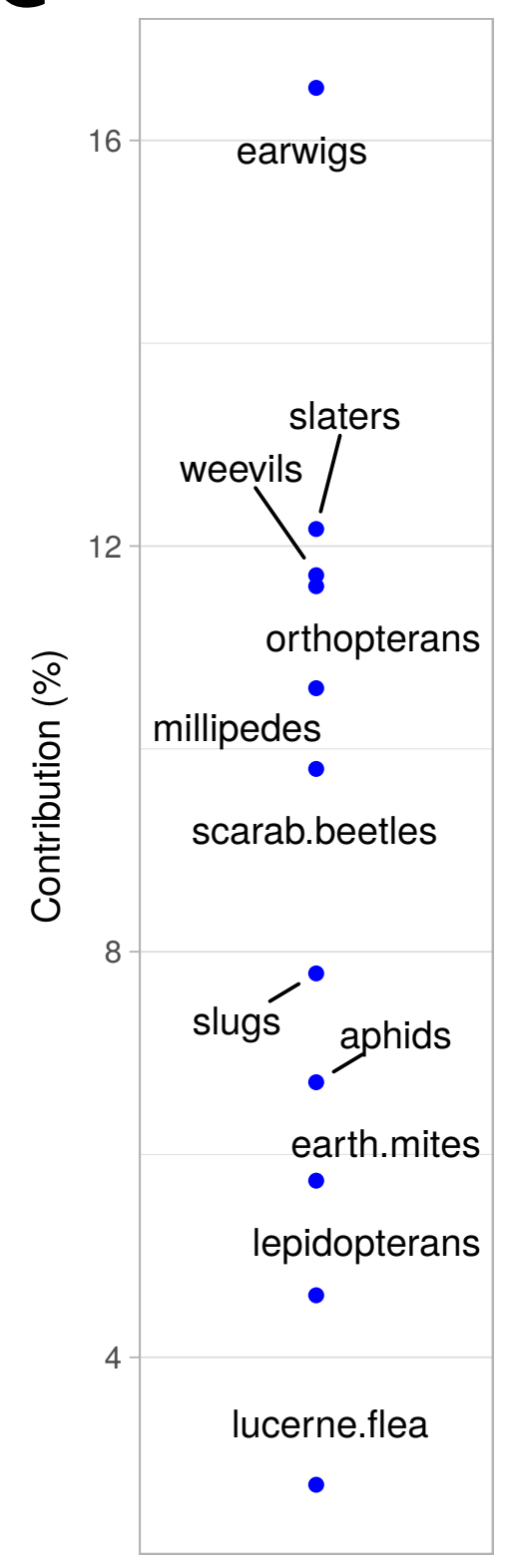


Figure 7 (on next page)

Yield

Yield (tonnes per hectare) per crop type and season, treatment and experimental transects (blocks 1-3). 


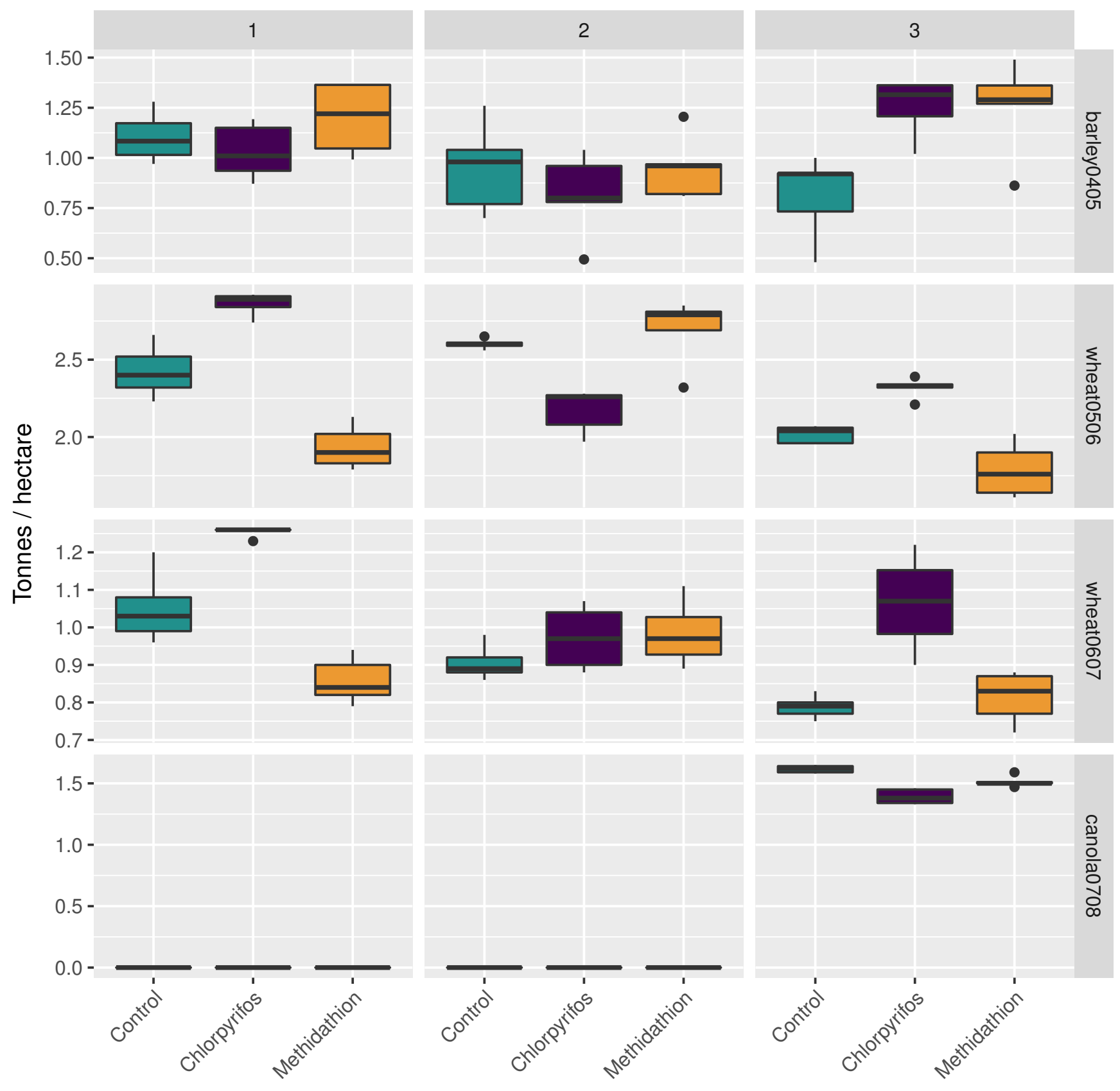

